\title{
An Overview Of Specialist Nurse Role In Patients With Stroke Caring And Their Care-Givers Support
}

\author{
Elham Navab ${ }^{1 *}$, Mehraneh Shali ${ }^{2}$ \\ ${ }^{1}$ Assistant Professor, Critical Care and M anagement department, School of nursing \& M idwifery, Tehran University of \\ Medical Sciences, Tehran, Iran. \\ ${ }^{2}$ Ph.D Student, Critical Care and Management Department, Tehran University of Medical Sciences, Tehran, Iran. \\ *Corresponding Author: Email: e-navab@sina.tums.ac.ir
}

Background: The practical difficulties for patients with stroke include lack of information about their condition, poor knowledge of the services and benefits available. Specialist Stroke nurses provide education and support services for people with Stroke in many health care systems. A key goal is helping and empowering unable people to self-manage their stroke and supporting caregivers of these valnurable population, too.

Objective: The objective of this review was to assess the role of specialist nurse in care for patients following a stroke and their caregivers support.

Search methods: The databases CINAHL, PubM ed, Science Direct and Synergy were searched from 1988 to 2017 using the keywords Stroke, Specialist Nurse, Care, Caregivers and support. Bibliographies of relevant papers were searched, and hand searching of relevant publications was undertaken to identify additional Studies.

Selection criteria: All studies of the effects of a specialist nurse practitioner on short and long term stroke outcomes were included in the review.

Data collection and analysis: Three investigators performed data extraction and quality scoring independently; any discrepancies were resolved by consensus.

Findings: Stroke, Specialist Nurse, Care, Caregivers concepts and labels are defined and measured in different and often contradictory ways by using 31 founded study.

Conclusions: The findings indicate a dissonance in the views of different stakeholders within the care system. The division of labour associated with nursing care and specialist nurse requires further exploration. The contrasting paradigms of health care professionals and people with stroke regarding models of disability were highlighted. Stroke, like other chronic illnesses, requires substantial nursing care. There is a growing number of specialist nurses in the workforce, however, little is known how their role interfaces with other nurses.

Keywords: Stroke, Specialist Nurse, Care, Caregivers

DOI: $10.7575 /$ aiac.abcmed.ca1.61

Published Date: February 2017

Peer-review is under responsibility of the 9th Iranian Stroke Congress.

Published by Australian International Academic Centre, Australia

This published work is open access under the CC BY license.

Available online at www.abcmed.aiac.org.au 